\title{
Зависимость содержания вторичных метаболитов в хвое разного возраста Juniperus sibirica от параметров азотного питания почв Хибин
}

\section{Артемкина Н.А.}

Институт проблем промышиленной экологии Севера, ФИЦ КНЦ РАH, Anamumbl, artemkina@inep.ksc.ru

Аннотация. В статье приведены данные по зависимости содержания отдельных групп химических элементов в разновозрастной хвое вечнозеленого низкорослого хвойного кустарника Juniperus sibirica Burgsd от содержания азота в почвах в высотном градиенте. Была установлена положительная корреляция между лигнином, липидами в старой хвое Juniperus sibirica, а также отрицательная корреляция между фенольными соединениями и танинами в молодой хвое Juniperus sibirica и содержанием азота в почвах.

Ключевые слова: Juniperus sibirica, лигнин, липиды, фенольные соединения, танины, флавоноиды, азот в почвах.

\section{Relationship between the content of secondary metabolites in needles of mixed-age Juniperus sibirica and the parameters of nitrogen nutrition of the Khibiny soils}

Artemkina N.A.

Institute of North Industrial Ecology Problems, Kola Science Centre RAS, Apatity, artemkina@inep.ksc.ru

Abstract. The article presents data on the relationship between the content of individual groups of chemical elements in the evergreen coniferous shrub Juniperus sibirica Burgsd and the nitrogen content in soils in the altitude gradient. A positive correlation has been defined between lignin, lipids in mature needles of Juniperus sibirica, as well as a negative correlation between phenolic compounds and tannins in young needles Juniperus sibirica and nitrogen content in soils.

Key words: Juniperus sibirica, lignin, lipids, phenolic compounds, tannins, flavonoids, nitrogen in soils.

\section{Введение}

Растения бореальных лесов, как правило, отличаются высоким содержанием, так называемых защитных составов - вторичных метаболитов, и соответственно, их показатели скорости разложения опада замедленные. Среди вторичных метаболитов наиболее обширной группой природных веществ являются фенольные соединения (Cohen, Kennedy, 2010). В процессе старения листьев/хвои фенольные соединения вымываются из растений и попадают в почву, замедляя, таким образом, скорость разложения растительного опада (Артемкина и др., 2018). Фенилпропаноиды играют большую роль в регулировании питательного вещества почвы, могут уменьшить минерализацию азота $(\mathrm{N})$, ингибировать микробную деятельность и тем самым снижать доступность азота для растений (Hättenschwiler, Vitousek, 2000).

Согласно одной из существующих гипотез «углерод/элементы питания» («carbon/nutrient balance - CNB») (Bryant et.al., 1983) процессы вегетативного роста растений господствуют над производством вторичных метаболитов при благоприятных для роста условиях. Увеличение содержания вторичных метаболитов происходит только тогда, когда рост растения ограничен нехваткой минеральных элементов питания, в частности азота.

Проведенный метаанализ данных, основанный на экспериментах с добавлением N с участием 35-ти древесных разновидностей растений, поддержал предсказанные различия: с увеличением азотного питания значительно уменьшились концентрации фенилпропаноидов, но не терпеноидов и гидролизуемых танинов, что авторы объясняют различиями в биосинтетической тропе (Haukioja et.al., 1998).

Недавние исследования скандинавских ученых (De Long et.al., 2016) показали, что более теплая температура и лучшая доступность азота (N) увеличивается из-за глобального изменения кли- 
мата, а содержание вторичных метаболитов в бореальной растительности уменьшается, особенно в пределах разновидностей. Работу проводили в высотном градиенте (500, 800, 1000 м), изучали восемь видов растений: B. nana (800, 1000 м), Calamagrostis lapponica Wahlenb. (800, 1000 м), Cassiope tetragona D. Don (1000 м), Deschampsia flexuosa L. (500 M), Empetrum hermaphroditum L. (500, 800, 1000 м), Vaccinium myrtillus L. (500 м), V. uliginosum L. (800, 1000 м) and V. vitis-idaea L. (500, 800, 1000 м). Определили, что добавление азота (N) уменьшило содержание танинов в молодых и старых (опадающих) листьях, фенольных соединений в старых (опадающих) листьях. Однако, концентрации лигнина не зависели от повышения азотного питания, возможно, что увеличение азота в почвах не действует на структурные компоненты в данной системе исследования.

В Хибинах произрастает вечнозеленый низкорослый хвойный кустарник Juniperus sibirica Burgsd. Предварительно мы установили, что по мере старения в хвое можжевельника происходит накопление липидов, фенольных соединений, лигнина и понижение концентраций растворимых и связанных конденсированных танинов, флавоноидов. С увеличением высоты произрастания (в березовых лесах) обнаружено достоверное снижение содержания лигнина, целлюлозы и липидов в многолетней хвое можжевельника по сравнению с еловыми лесами. Содержание фенилпропаноидов, флавоноидов, растворимых и связанных конденсированных танинов в еловых и березовых лесах было сопоставимо (Артемкина и др., 2016).

Данное исследование направлено на изучение зависимости содержания вторичных метаболитов в хвое разного возраста Juniperus sibirica от параметров азотного питания в высотном градиенте.

В Хибинских горах формируется особый микроклимат - количество атмосферных осадков здесь в 1.5-2 раза выше, чем на равнине. Средняя температура в Хибинах составляет приблизительно $-2.0^{\circ} \mathrm{C}$, в январе $-12.3^{\circ} \mathrm{C}$, а в июле $+10.3^{\circ} \mathrm{C}$. До высоты 300-400 м у подножий гор и на их склонах еловые леса различных типов сформированы в основном елью сибирской (Picea obovata). Выше 400 м леса и редколесья формирует береза Черепанова (Betula pubescens ssp. czerepanovii (Orlova) Hamet-Ahti).

Отбор образцов хвои текущей, 1-летней и 3-7-летней, а также подстилки почв проводили в трёхкратной повторности на г. Саами (6770' с.ш., $33^{\circ} 79^{\prime}$ в.д.) в ельниках деренно-кустарничковозеленомошных (ниже 300-400 м) и березняках кустарничково-зеленомошных (выше 400 м). В напочвенном покрове доминируют кустарнички и зеленые мхи, а также дерен шведский, мелкотравье и злаки. Можжевельник формирует в еловых и березовых лесах Хибин отдельные островки.

Общее содержание $\mathrm{N}$ определяли методом Къельдаля. Содержание лигнина определяли путем обработки пробы $72 \%$-ной серной кислотой как представлено в работе (Lukina et.al., 2017). Концентрацию липидов, фенольных соединений, конденсированных танинов устанавливали методами, описанными в статье (Артемкина и др., 2016). Сумму флавоноидов определяли фотоколориметрическим методом (410 нм) после реакции полученного извлечения с $0.05 \mathrm{M}$ раствором $\mathrm{AlCl}_{3}$ в этаноле (Артемкина, 2010).

Из-за различной роли молодой и старой хвои, устанавливать количество вторичных метаболитов в обоих типах хвои важно для понимания роли этих химических соединений в различных экологических процессах. Мы объединили текущую и 1-летнюю хвою и обозначили как «молодая хвоя», а хвою 3-7-летнюю как «старая хвоя».

На рисунке представлены некоторые зависимости содержания вторичных метаболитов от параметров азотного питания в высотном градиенте. Для почв вдоль этого градиента предыдущие исследования показали, что уменьшение доступного растениям азота в L-подгоризонте подстилки связано с увеличением высоты (Артемкина и др., 2016).

Содержание лигнина в молодой хвое можжевельника не зависит от концентрации азота $(\mathrm{N})$, в то время как в старой хвое концентрации лигнина достоверно уменьшаются при недостатке азотного питания. Японские ученые предположили, что более низкое содержание лигнина является адаптивной реакцией и облегчает более быструю рециркуляцию питательных веществ в окружающих средах с меньшей продуктивностью (высокое возвышение) (Kitayama et.al., 2004). 

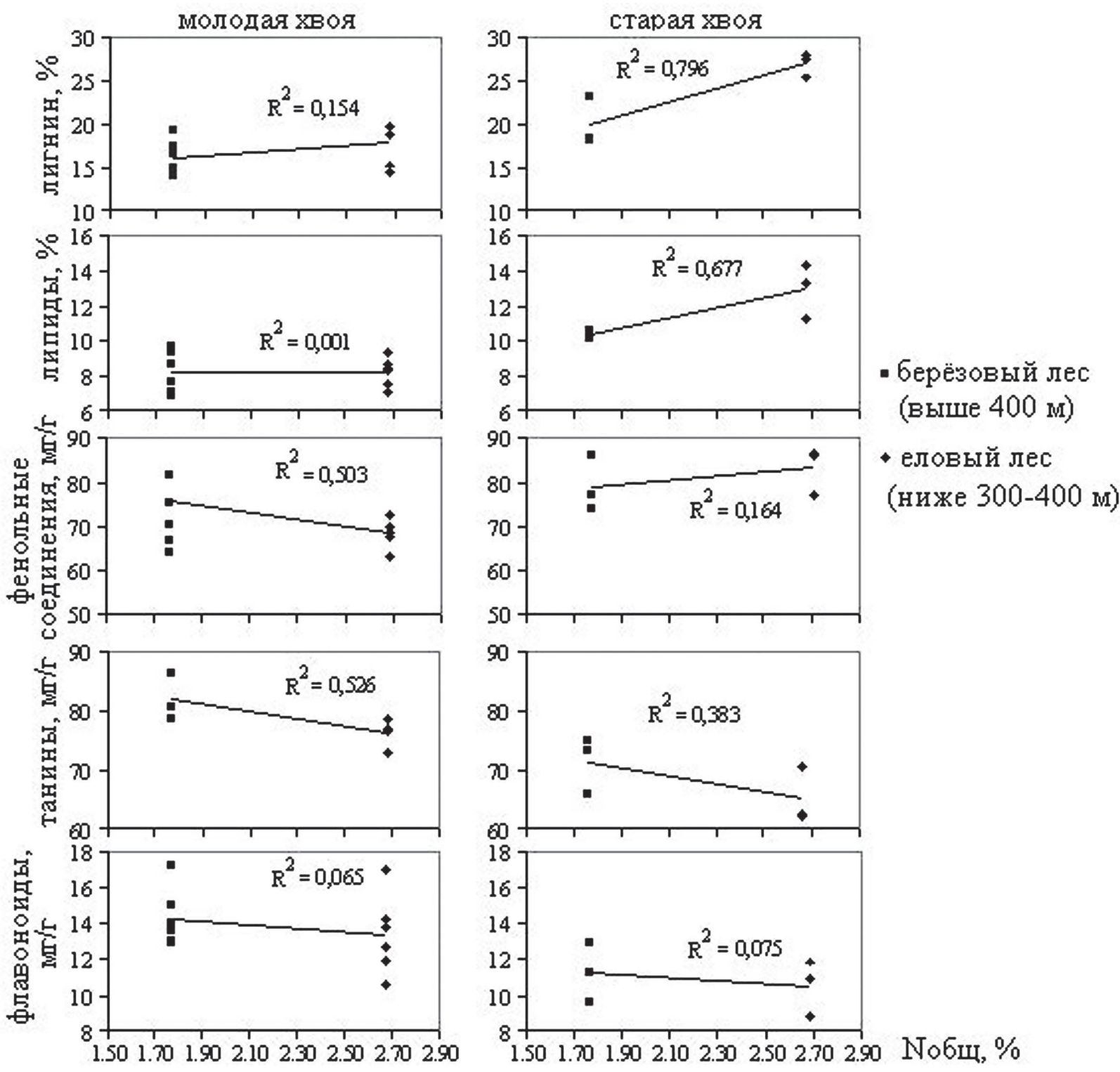

Рис. Зависимость содержания отдельных классов вторичных метаболитов в молодой и старой хвое Juniperus sibirica от параметров азотного питания почв в высотном градиенте $(p<0.05)$.

Fig. Relationship between the content of certain classes of secondary metabolites in young and mature needles of Juniperus sibirica and the parameters of nitrogen nutrition of soils in the altitude gradient $(\mathrm{p}<0.05)$.

Прежде мы также находили положительную корреляцию содержания лигнина, но с другими элементами питания (K, Mn, Р), которые стимулируют процессы лигнификации в хвое Picea abies (Артемкина и др., 2019).

Подобная картина характерна и для липидов. Отсутствие каких-либо изменений от содержания азота в молодой хвое и снижение количества липидов в старой хвое можжевельника, произрастающего на почвах с пониженным питательным статусом. Ранее было установлено, что изменения в ответах вторичных метаболитов в древесных растениях при увеличении $\mathrm{N}$ имеет биосинтетическую причину (Haukioja et.al., 1998). Синтез фенилпропаноидов с ростом растения конкурирует непосредственно с синтезом белков, из-за общего предшественника, фенилаланина. Напротив, биосинтез терпеноидов (один из основных классов соединений, входящих во фракцию липидов) проходит, вероятно, без прямой конкуренции с синтезом белка. Поэтому, ускоренный рост растения, вызванный усилением азотного питания, может не затронуть уровни терпеноидов. То есть здесь, скорее всего, работают другие причины влияния на содержание липидов в высотном градиенте, а имен- 
но, более низкая скорость фотосинтеза в хвое можжевельника с повышением высоты, что приводит к торможению развития хлоропластов в клетках мезофилла, из-за чего наблюдается низкое содержание пигментов (Герлинг, Загирова, 2009).

В молодой хвое Juniperus sibirica содержание суммы фенольных соединений и танинов отрицательно связаны с концентрациями азота в L-подгоризонте подстилки. Это согласуется с теорией «углерод/элементы питания» (CNB) (Bryant et.al., 1983), основной смысл которой заключается в том, что при достаточном количестве элементов питания доминирует вегетативный рост растения, а синтез вторичных метаболитов ограничен. В старой хвое Juniperus sibirica сумма фенольных соединений слабо зависит от количества азота в L-подгоризонте подстилки, в то время как танины проявляют устойчивую тенденцию к отрицательной корреляционной связи с почвенным азотом. Такие результаты согласуются с ранее проведенными исследованиями, в которых представлено, что концентрации суммы фенольных соединений и танинов молодых и старых (опадающих) листьев восьми видов растений уменьшаются при повышении доступности азота. Ученые также нашли, что отклики этих классов вторичных метаболитов на взаимодействие с почвенным азотом и высотным градиентом были, прежде всего, объяснены внутривидовым изменением химического состава, чем межвидовым (De Long et.al., 2016). Особенно можно подчеркнуть отрицательную взаимосвязь конденсированных танинов хвои Juniperus sibirica с N в почве, подобные данные были получены нами для конденсированных танинов молодой хвои Picea abies $\times$ obovata, произрастающих в различных элементарных биогеоареалах (ЭБГА) в ельниках кустарничково-зеленомошных (не опубликованные данные).

Содержание флавоноидов хвои можжевельника по нашим данным не зависит от условий азотного питания почв. Флавоноиды в основном выполняют защитную функцию от фотоокислительного повреждения (Close, Mcarthur, 2002) и быстро уменьшаются во время старения хвои/листьев (Артемкина и др., 2016).

Таким образом, в результате исследования были выявлены взаимосвязи содержания отдельных классов вторичных метаболитов (лигнин, липиды, фенольные соединения, конденсированные танины, флавоноиды) в молодой и старой хвое Juniperus sibirica от параметров азотного питания почв в высотном градиенте. Различные классы вторичных метаболитов по-разному реагируют на изменение содержания азота в почвах. Установили положительную корреляционную зависимость между концентрациями лигнина, липидов в старой хвое Juniperus sibirica и содержанием N в почвах. Для фенольных соединений и танинов наблюдается обратная картина в молодой хвое Juniperus sibirica: уменьшение количества этих вторичных метаболитов происходит только тогда, когда увеличивается азот в почве. Содержание флавоноидов хвои можжевельника не зависит от условий азотного питания почв.

Работа выполнена в рамках темы НИР № 0226-2018-0111.

\section{Литература}

1. Артемкина H.A. Содержание фенольных соединений в V. vitis-idaea L. сосновых лесов Кольского полуострова // Химия растительного сырья. 2010. № 3. С. 153-160.

2. Артемкина Н.А., Лукина Н.В., Орлова М.А. Пространственное варьирование содержания вторичных метаболитов, углерода и азота в подстилках северотаежных ельников // Лесоведение. 2018. № 1. С. 37-47.

3. Артемкина Н.А., Орлова М.А., Лукина Н.В. Пространственное варьирование содержания фенольных соединений и элементов питания в хвое ели северотаежных лесов // Лесоведение. 2019. № 4. (в печати).

4. Артемкина Н.А., Орлова М.А., Лукина Н.В. Химический состав хвои Juniperus sibirica (CUPRESSACEAE) в экотоне лес-тундра, Хибинские горы // Экология. 2016. № 4. С. 243-250.

5. Герлинг Н.В., Загирова С.В. Структура и фотосинтез хвои Juniperus sibirica (Cupressaceae) на Северном Урале // Ботанический журнал. 2009. Т. 94. № 11. С. 1672-1680.

6. Bryant J.P., Chapin F.S. III, Klein D.R. Carbon:nutrient balance of boreal plants in relation to vertebrate herbivory // Oikos. 1983. V. 40(3). P. 357-368.

7. Close D.C., Mcarthur C. Rethinking the role of many plant phenolics - protection from photodamage not herbivores? // Oikos. 2002. V. 99(1). P. 166-172. 
8. Cohen S.D., Kennedy J.A. Plant metabolism and the environment: implications for managing phenolics // Critical reviews in food science and nutrition. 2010. V. 50(7). P. 620-643.

9. Hättenschwiler S., Vitousek P.M. The role of polyphenols in terrestrial ecosystem nutrient cycling // Trends in Ecology and Evolution. 2000. V. 15(6). P. 238-243.

10. Haukioja E., Ossipov V., Koricheva J., Honkanen T., Larsson S., Lempa K. Biosynthetic origin of carbon-based secondary compounds: cause of variable responses of woody plants to fertilization? // Chemoecology. 1998. V. 8(3). P. 133-139.

11. De Long J.R., Sundqvist M.K., Gundale M.J., Giesler R., Wardle D.A. Effects of elevation and nitrogen and phosphorus fertilization on plant defence compounds in subarctic tundra heath vegetation // Functional ecology. 2016. V. 30(2). P. 314-325.

12. Kitayama K., Suzuki S., Hori M., Takyu M., Aiba S.I., Majalap-Lee N., Kikuzawa K. On the relationships between leaf litter lignin and net primary productivity in tropical rain forests // Oecologia. 2004. V. 140(2). P. 335-339.

13. Lukina N.V., Orlova M.A., Steinnes E., Artemkina N.A., Gorbacheva T.T., Smirnov V.E., Belova E.A. Mass-loss rates from decomposition of plant residues in spruce forests near the northern tree line subject to strong air pollution // Environmental Science and Pollution Research. 2017. V. 24(24). P. 19874-19887. 